\title{
SINERGIA
}

REVISTA DO INSTITUTO DE CIÊNCIAS ECONÔMICAS, ADMINISTRATIVAS E CONTÁBEIS (ICEAC)

\section{GESTÃO ESTRATÉGICA DE DESEMPENHO: UMA AVALIAÇÃO DO IMPACTO DA ATIVIDADE REMUNERADA EM PERÍODO INTEGRAL NO DESEMPENHO ACADÊMICO DOS DISCENTES DO CURSO DE ENGENHARIA DE PRODUÇÃO DA UNIVERSIDADE FEDERAL DE PELOTAS (UFPEL)}

\author{
BRUNO DUTRA \\ ETIENE VILLELA MARRONI* \\ ARIANE FERREIRA PORTO ROSA \\ ROGÉRIO ROYER ${ }^{*+*}$
}

\begin{abstract}
RESUMO
A gestão de desempenho é uma importante ferramenta para a mensuração e melhoria de performance dos indivíduos e, consequentemente, das organizações. Esta ferramenta permite o acompanhamento dos objetivos e o alinhamento das estratégias, junto aos indivíduos envolvidos nos processos organizacionais, permitindo um maior engajamento e uma maior qualidade nos resultados obtidos. Já o desempenho acadêmico é composto por uma série de fatores, de forma a não haver uma definição universal do conceito. Porém, ele costuma ser mensurado por conceitos ou notas atribuídas a determinadas atividades avaliativas. Dessa forma, o presente trabalho tem como objetivo a avaliação da autopercepção de desempenho acadêmico dos discentes do curso de Engenharia de Produção da Universidade Federal de Pelotas (UFPel). A avaliação deu-se por meio de um questionário fechado, composto por dezessete questões, as quais serviram para uma classificação dos discentes conforme sua posição no mercado de trabalho, bem como base de análise dos dados, divulgação de resultados e propostas de melhorias visando esclarecer a autopercepção dos alunos no tocante ao desempenho acadêmico. A quantificação das respostas deu-se através da aplicação da escala Likert, com posterior nivelamento, de acordo com a criticidade de cada questão sob a ótica dos discentes. O estudo possibilitou a verificação dos pontos que os discentes consideram mais críticos em relação ao seu próprio desempenho acadêmico. Esta avaliação tem grande importância para o norteamento de ações dos discentes, principalmente, os que exercem atividades laborais em período integral, permitindo, assim, um avanço no rendimento em relação aos estudos na Universidade. Na conclusão deste estudo, observa-se que o desempenho acadêmico dos discentes que não trabalham é superior ao desempenho dos demais, porém, apesar do grupo de discentes que estagiam apresentar uma maior disposição a frequentar a Universidade para atividades extracurriculares, este grupo apresentou o menor rendimento acadêmico, sendo um pouco inferior ao dos que trabalham em período integral. Com isso, foi possível atingir os objetivos propostos, a metodologia que complementa e endossa a complexidade de variáveis envolvidas no desempenho acadêmico dos discentes, bem como novas propostas e um conjunto de ações que podem auxiliar na melhoria da autopercepção dos discentes quanto ao seu desempenho acadêmico.
\end{abstract}

Palavras-chave: Autopercepção, Rendimento, Desempenho, Gestão estratégica. Engenharia de produção.

\section{ABSTRACT}

Performance management is an important tool for measuring and improving the performance of individuals and, consequently, organizations. This tool allows the monitoring of objectives and the alignment of strategies, with the individuals involved in the organizational processes, allowing for greater engagement and greater quality in the results obtained. Academic performance, on the other hand, is composed of a series of factors, so that there is no universal definition of the concept. However, it is usually measured by concepts or grades, attributed to certain evaluative activities. Thus, the present work aims to evaluate the self-perception of academic performance of students in the Production Engineering course at the Federal University of Pelotas (UFPel). The evaluation took place through a closed questionnaire, composed of seventeen questions, which served to classify students according to their position in the labor market, as well as the basis for data analysis, dissemination of results and proposals for improvements in order to clarify students' self-perception regarding academic performance. The quantification of responses occurred through the application of the Likert scale, with subsequent leveling, according to the criticality of each question from the students' perspective. The study enabled the verification of the points that the students consider most critical in relation to their own academic performance. This evaluation is of great importance for guiding the actions of students, especially those who work full time, thus allowing an advance in performance in relation to studies at the University. At the conclusion of this study, it is observed that the academic performance of students who do not work is superior to the performance of the

\footnotetext{
*Engenheiro de Produção pela Universidade Federal de Pelotas (UFPEL).

** Doutora em Ciência Política. Mestre em Educação Ambiental. Docente da Universidade Federal de Pelotas (UFPel).

*** Doutora em Automatique et Informatique Appliquées (Spécialité Génie Industriel Qualité), pela Université de Nantes. Mestre em Engenharia de Produção pela Universidade Federal do Rio Grande do Sul. Pos-Doutora na Ecole des Mines de Nantes. Docente do curso de Engenharia de Produção do Centro de Engenharias na UFPel. E-mail: afprosa61@gmail.com

Doutor em Administração pela Universidade Federal do Rio Grande do Sul. Mestre em Engenharia de Produção pela Universidade Federal do Rio Grande do Sul. Docente da Universidade Federal de Pelotas (UFPel).
} 
others, but despite the group of students who were internship presented a greater willingness to attend the University for extracurricular activities, this group had the lowest performance academic, being slightly inferior to those who work full time. With this, it was possible to achieve the proposed objectives, the methodology that complements and endorses the complexity of variables involved in the academic performance of students, as well as new proposals and a set of actions that can help improve the students' self-perception of their academic performance.

Keywords: self-perception, performance, strategic management. Industrial engineering.

Recebido em: 29-04-2021 Aceito em: 16-07-2021

\section{INTRODUÇÃO}

Atualmente, existe uma demanda crescente por profissionais altamente qualificados e capacitados, impulsionada pela grande competitividade do mercado de trabalho. Essa alta concorrência pelas vagas de emprego tende a crescer devido à série de incertezas e de mudanças constantes que o país tem enfrentado nas esferas econômica, política e, principalmente, educacional. Segundo o Censo INEP/MEC (2018), no ano de 2018, havia 8.451.748 alunos matriculados no ensino superior, aproximadamente, $44,64 \%$ mais do que em 2008, e 1,9\% a mais do que o ano anterior, 2017. De maneira que, durante os últimos 10 anos, houve um crescimento anual médio de 3,8\%. Ainda, nos é apresentado que as Instituições de Ensino Superior (IES) públicas são responsáveis por cerca de $75,4 \%$ destas matrículas.

Dentre uma série de fatores que justificam esta procura por IES públicas, cabe destacar duas: a qualidade e a gratuidade do ensino. A qualidade do ensino superior público, no país, destaca-se nacionalmente e internacionalmente. Das 46 Universidades brasileiras que aparecem no The World University Rankings (2019), 39 são instituições públicas. A Universidade Federal de Pelotas (UFPel) consta entre as mil melhores do mundo em 2020, entre as 250 melhores universidades jovens do ano de 2019 e está entre as 60 melhores da América Latina, segundo o mesmo ranking.

Além da qualidade do ensino, as condições socioeconômicas dos indivíduos têm um papel importante na escolha pelas IES públicas. Esses futuros estudantes, muitas vezes, não possuem condições de pagar ou financiar um curso em uma IES privada. Esta situação agrava-se em áreas que demandam recursos tecnológicos avançados ou maior quantidade de funcionários, elevando os custos de mensalidade e materiais e, consequentemente, da formação do discente, conforme estudo realizado por Magalhães (2010) na Universidade Federal de Viçosa. O Mapa do Ensino Superior, do ano de 2017, traz uma média de custos por cursos, em que os mais onerosos aos alunos são: cursos de engenharia, com média de $\mathrm{R} \$ 1.100$; arquitetura e urbanismo, com média de $R \$ 1.200$; odontologia, com média de $R \$ 2.100$ e medicina, com a média de $\mathrm{R} \$ 6.200$ de mensalidade.

Segundo o INEP, a taxa de evasão universitária se manteve estável ao longo da última década, ficando em torno de $21 \%$, porém, mesmo com o caráter estável desta taxa, o contínuo crescimento de matrículas faz com que este percentual signifique que mais de um milhão de estudantes deixam o curso superior antes da conclusão, todos os anos. A evasão universitária é caracterizada pelo trancamento de matrícula por prazo indeterminado ou pela desistência do aluno, antes da conclusão do curso. Diversos autores apontam que os níveis de evasão podem chegar até a $50 \%$ do número total de matrículas, cuja grande maioria dos casos se concentram nos primeiros semestres dos cursos (BARDAGI \& HUTZ, 2009).

Vários são os fatores que impactam no desempenho acadêmico e, consequentemente, na taxa de evasão do ensino superior. Machado et al. (2005), em um estudo na UFRJ, constataram que três fatores se destacam ante os demais quanto à evasão: (1) a idade do aluno no momento da escolha do curso, o que pode acarretar incerteza sobre a escolha do curso de formação; (2) a chamada "falsa evasão", que se dá devido à mudança para outra IES; e (3) o abandono de curso por questões financeiras, causa típica de grandes cidades, principalmente, em cursos de período integral (manhã e tarde), uma vez que, nesses cursos, os estudantes são impedidos de frequentar as aulas, pois são obrigados a trabalhar para custeio próprio ou para complementar a renda familiar.

Ferreti e Madeira (1992) constataram que, há quase trinta anos, os alunos alteraram o perfil de apenas estudantes para estudantes trabalhadores, dada a necessidade de complementar a renda familiar e educacional. Os autores afirmam, também, que, ainda na década de 90, alunos de baixa renda escolhiam por IES particulares. Esta escolha baseava-se, principalmente, na falta de tempo para a conciliação do trabalho e estudo, visto que, nas IES públicas, grande parte dos cursos são integrais.

Nos dias de hoje, as IES públicas têm tentado se adaptar a esta realidade, ofertando cursos no período noturno, proporcionando maiores condições de permanência aos alunos que necessitam de um trabalho de período integral. Na Universidade Federal de Pelotas, o curso de Engenharia de Produção (EP) destaca-se como exemplo por ser o único curso de engenharia noturno do Centro de Engenharias (CEng). A EP é uma das mais concorridas engenharias da UFPel, além de concentrar a maioria dos estudantes trabalhadores. Acredita-se que muitos desses alunos acabam optando pela EP, justamente pela possibilidade de conciliar 0 
trabalho com o estudo, deixando em segundo plano a parte específica do curso.

A Gestão de Desempenho é uma importante ferramenta para o desenvolvimento de indivíduos e, consequentemente, de organizações. Para Aguinis (2013), ela é definida como um processo de análise e desenvolvimento contínuo dos indivíduos em relação ao desempenho, bem como o alinhamento deste desempenho com os objetivos da organização. Adaptando os conceitos de gestão de desempenho para o curso de Engenharia de Produção da UFPel, tornou-se possível compreender os principais fatores que impactam negativamente o desempenho acadêmico dos discentes, além de determinar se a atividade remunerada, em período integral, atua como um gargalo no desenvolvimento dos mesmos.

Utilizando-se de fundamentos de Estratégia Organizacional e Gestão de Desempenho, este artigo tem por objetivo analisar o desempenho acadêmico dos discentes do curso de EP que trabalham em relação aos que somente estudam. Posteriormente, trazer propostas de otimização e soluções para o ganho de desempenho, de forma a minimizar os gargalos de aprendizado. O estudo pretende, ainda, fornecer evidências que ajudem os docentes a tomarem melhores decisões em relação a atividades discentes e, potencialmente, provocar mudanças em suas abordagens didáticas.

\section{REFERENCIAL TEÓRICO}

Nesta seção, será apresentada uma revisão da literatura utilizada na composição deste artigo. Nele, serão abordados temas relacionados ao desempenho acadêmico no ensino superior através das perspectivas de diversos autores. Abordando, ainda, a relação entre a escolaridade e o desemprego com o acesso e a com a qualidade de ensino aos alunos, bem como tópicos de estratégias organizacionais e gestão de desempenho.

\subsection{Desemprego e Escolaridade}

Nos últimos anos, o Brasil tem passado por uma série de instabilidades político-econômicas, as quais ainda se mantêm, no ano de 2020. Essas instabilidades têm trazido efeitos negativos ao mercado de trabalho. Segundo o Index Mundi (2018), que utiliza o banco de dados da Central Intelligence Agency (CIA), as taxas de desemprego no país apresentavam forte queda no período compreendido entre os anos de 2002 e 2013 , porém, após este período, o aumento da taxa de desempregados no país foi expressivo, chegando ao recorde histórico de quase 14 milhões em 2017, como ilustrado na Figura 1.

Figura 1 - Dados históricos desemprego no Brasil

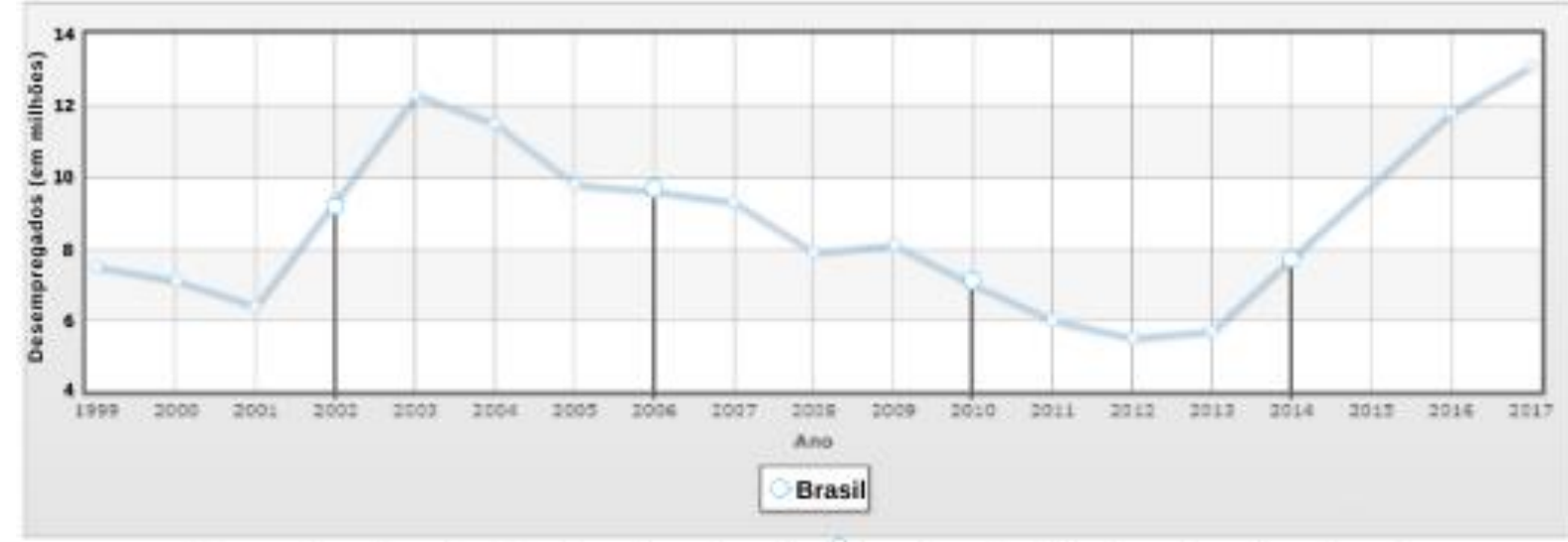

\begin{tabular}{|l|r|r|r|r|r|r|r|r|r|r|r|r|r|r|r|r|}
\hline Pais/Ano & 1999 & 2000 & 2001 & 2003 & 2004 & 2005 & 2006 & 2007 & 2008 & 2009 & 2010 & 2011 & 2012 & 2013 & 2016 & 2017 \\
\hline Brasil & 7.5 & 7,1 & 6.4 & 12.3 & 11,5 & 9,8 & 9,6 & 9,3 & 79 & 8.1 & 7 & 6 & 5.5 & 5.7 & 11.8 & 13,1 \\
\hline
\end{tabular}

Fonte: CIA World Factbook, 2018.

Pereira et al. (2018) evidenciam que, no período compreendido entre o ano de 2010 e o ano de 2014 houve uma tendência de queda nas taxas de desemprego, porém, a partir do ano de 2015, ocorreu a inversão desta tendência, em que a taxa de desempregados passou de 6,6 milhões, no ano de 2014, para 12,9 milhões no início do ano de 2017, ou seja, um aumento de 95,45\% em três anos. Ainda segundo este estudo, entre os anos 2012 e 2016, a faixa de trabalhadores que teve o maior crescimento em participação no mercado de trabalho foi a dos que possuíam o ensino superior completo, a qual passou de $11,5 \%$ para $14,1 \%$, representando um crescimento de $22,6 \%$.

O MEC (2018) justifica este crescimento na parcela de trabalhadores graduados pela expansão da educação superior, uma vez que uma série de programas foram criados desde o ano de 2004, ao exemplo 
do Programa Universidade para Todos (Prouni) e do Sistema de Seleção Unificada (Sisu), bem como do Programa de Apoio a Planos de Reestruturação e Expansão das Universidades Federais (Reuni), o qual possibilitou a criação da EP na UFPel, que permitiu uma grande ampliação das IES e, consequentemente, as chances de ingresso em um curso superior.

Barroso (2010) constatou que, entre os anos de 1993 e 2008, no estado do Rio Grande do Sul, houve um aumento na participação de indivíduos com curso superior no mercado de trabalho, indo de $8,3 \%$ no ano de 1996 para 13,6\% em 2008. Ainda segundo este estudo, neste mesmo período, houve um acréscimo considerável na taxa de desempregados com ensino médio completo, saltando de $14,8 \%$ para $36,2 \%$, o que vem de encontro com o aumento nos números de matrículas nas IES, uma vez que estes indivíduos passaram a procurar uma maior qualificação profissional, sendo que o próximo passo é o ensino superior.

Dados do Instituto Brasileiro de Geografia e Estatística (2019) endossam que o percentual de desempregados com ensino superior completo é consideravelmente menor do que os demais graus de instrução, os quais representam cerca de $6,9 \%$, enquanto os que possuem o ensino médio incompleto figuram na maior parcela de desempregados, com um percentual de $22,1 \%$.

\subsection{Estratégia Organizacional}

Cada vez mais, a estratégia organizacional aumenta sua importância no cotidiano das organizações, independente do porte ou do segmento das empresas. Para Alday (2000), a utilização da estratégia organizacional permite que a organização enxergue saídas para contornar as adversidades, sejam internas ou externas, bem como permite o aproveitamento das oportunidades oferecidas pelo ambiente na qual a organização está inserida.

Segundo Chandler (1962), a estratégia nada mais é do que o conjunto de pequenas metas e objetivos de longo prazo, bem como a alocação e a distribuição dos recursos necessários para a obtenção de sucesso desses objetivos. Já Coelho (2004) caracteriza as organizações como as responsáveis pela manufatura de bens e serviços no intuito de satisfazer as necessidades da sociedade. De acordo com estas definições, combinando-as, podemos adequar a estratégia organizacional para toda e qualquer organização, seja pública ou privada, incluindo as instituições de ensino que oferecem seus serviços, na esfera educacional, para satisfazer as necessidades de crescimento e conhecimento que a sociedade moderna e o mercado de trabalho demandam.

Atualmente, o estudo da estratégia organizacional já não se restringe mais apenas às empresas de manufatura de bens privadas. Fortemente impulsionada pela contenção de gastos e/ou pela procura de um ganho produtivo significativo, a estratégia organizacional tem sido largamente aplicada às mais variadas organizações, incluindo as IES, sejam privadas ou públicas, cada qual com seus objetivos, desde maior atração e agregação de valor até diminuição de taxas de evasão e aumento da produção de pesquisas.

Para Camargo e Dias (2003), a estratégia organizacional deve estar constantemente se adequando ao ambiente e ao tempo em que organização está inserida, permitindo, assim, uma maior agregação de valores a seus serviços frente a seus stakeholders. Segundo Weick (1976), as instituições de ensino podem ser consideradas sistemas fortemente articulados, uma característica inerente e diferenciada deste tipo de organização. Esse fato permite que as IES adequem suas estratégias organizacionais às regiões e culturas em que estão inseridas, de forma a atender às necessidades da sociedade e ao mercado ao seu entorno.

No contexto das IES públicas, podemos ver estas adequações de estratégias, tendo como exemplo a criação da Lei 12.711 de 2012, a qual regulamenta o sistema de cotas em universidades e institutos federais. Esta adequação estratégica se deu por conta da criação do REUNI, o qual expandiu, em larga escala, as IES públicas, com a iniciativa de proporcionar uma maior representação da população do país nas universidades, uma vez que quase $56 \%$ da população brasileira é negra ou parda (IBGE, 2018).

\subsection{Gestão de Desempenho}

A gestão de desempenho (GD), ou gestão de performance, é uma importante ferramenta para a mensuração e melhoria de performance dos indivíduos e, consequentemente, das organizações. Esta ferramenta permite o acompanhamento dos objetivos e $\mathrm{o}$ alinhamento das estratégias junto aos indivíduos envolvidos nos processos organizacionais, permitindo um maior engajamento e uma maior qualidade nos resultados obtidos.

A GD vem passando por uma série de adaptações ao longo dos anos. Como apontam Jensen e Sage (2000), essas evoluções vêm acontecendo desde o estudo de tempos e movimentos de Taylor, do início do século XX, até as mais atuais premiações e certificações de excelência em qualidade, como as ISO (International Organization for Standardization). Para Sink e Tuttle (1989), a GD é uma sistemática em que ocorrem, de forma procedural e linear, as definições, planejamento e implementações das estratégias, alcançando toda a estrutura organizacional. Já Marçal (2008) diz que GD tem como objetivo o alinhamento 
das atitudes com a visão da empresa, se a mesma está conseguindo concretizar esta visão, que, no geral, tende a ser o crescimento orgânico e saudável, através de um processo de melhoria contínua no desempenho da organização, sem descartar os valores individuais, trazendo o lucro como consequência positiva.

A GD é mensurada através de indicadores, os quais têm vital importância para o acompanhamento dos objetivos definidos pela estratégia organizacional adotada. Hronec (1994) diz que o acompanhamento do desempenho possibilita a disseminação adequada da estratégia a todas as esferas da organização, possibilitando, assim, a compreensão da dimensão do envolvimento individual de cada um dos stakeholders, bem como o papel de cada no desenvolvimento e na evolução da organização.

Fonseca (1997) classifica os indicadores de desempenho em três vertentes: (a) custos, de forma geral, estão alinhados com a parte financeira e orçamentária; (b) qualidade, indicadores que mensuram o grau de satisfação com o resultado obtido fronte ao resultado esperado, seja em produto, seja em serviço prestado; (c) tempo, relacionado a velocidade e tempo de resposta aos pedidos de clientes, bem como a velocidade de reação a mudanças externas à organização. Segundo Brandão e Guimarães (2001), é preciso integrar o planejamento, acompanhamento e a avaliação de desempenho em um único modelo de gestão, em que são consideradas as competências vitais da organização, desde o nível corporativo até o nível individual, seguindo o conceito de melhoria contínua.

Adaptando os conceitos de GD para as IES públicas, podemos aplicar a gestão de performance tanto aos indivíduos integrantes da estrutura organizacional, os próprios colaboradores, como também aos clientes, alunos e sociedade, de forma a obter ganho produtivo real na atividade fim da Universidade, ou seja, no processo de ensino e aprendizado.

\subsection{Desempenho Acadêmico}

Diversos estudos apontam que o rendimento de um aluno está atrelado a uma série de variáveis, uma vez que existe uma série de fatores que impactam, diretamente, no rendimento acadêmico durante a graduação. Para Miranda et al. (2013), dentre os vários fatores, cabe destacar os seguintes: absenteísmo, desempenho escolar anterior, motivação, conhecimento prévio do conteúdo, área de atuação, entre outros. Esses fatos podem ser desdobrados em uma série de fatores como, por exemplo, a execução de atividade remunerada em meio período ou integral.

Podem ser encontrados alguns estudos que abordam o desempenho acadêmico nos cursos de Engenharia de produção no Brasil. Gautério e Mattos (2014) investigaram alguns indicadores do desempenho acadêmico (quantidade de estudantes por turma, taxa de evasão, taxa de reprovação e notas obtidas pelos estudantes) para tentar identificar um padrão de comportamento que possibilitasse implementar melhorias no processo de ensino-aprendizagem. A metodologia utilizada pelos autores foi quantitativa com aplicação de ferramentas estatísticas na amostragem realizada.

Sturm et al. (2015) analisaram os cursos brasileiros de graduação e de pós-graduação em Engenharia de Produção, considerando a ênfase do curso, as áreas de pesquisa, a situação geográfica e a sua classificação. Para isso, propuseram um estudo qualitativo e quantitativo, do tipo descritivo, tendo como plano de coleta dos dados uma pesquisa bibliográfica a partir dos dados disponibilizados nos sites da Associação Brasileira de Engenharia de Produção (ABEPRO) e do Ministério da Educação (e-MEC). No estudo, Sturm et al. (2015) apontam que, apesar do curso de graduação e de pós em Engenharia de Produção terem se desenvolvido no país, a sua distribuição é heterogênea e a qualidade se encontra aquém das necessidades do mercado.

\section{- Qualidade e Acesso do Ensino Básico}

O Brasil é um país ainda em desenvolvimento, com caráter de país emergente, ou seja, ainda carece de investimentos, principalmente, em educação para seu total desenvolvimento. A Pesquisa Nacional por Amostra de Domicílios Contínua (PNAD-Contínua, 2018) evidencia este fato, mostrando que, apesar de haver uma melhora em quase todos os indicadores educacionais, entre os anos de 2016 e 2018, o Brasil ainda apresenta índices baixos de acesso à educação básica à população com 25 anos ou mais.

Neste período de 2 anos, houve uma melhora de 2,4\% no acesso à educação básica, indo de $45 \%$ no ano de 2016, a 47,4\% no ano de 2018. Entretanto, a PNAD-Contínua apontou, ainda, que há uma grande disparidade neste indicador entre as regiões do país, sendo a maior diferença entre o Nordeste $(38,9 \%)$ e o Sudeste $(53,6 \%)$. Além de também haver grande variação entre brancos $(55,8 \%)$ e negros e pardos $(40,3 \%)$, esses indicadores evidenciam que a educação, ainda, não é para todos no país.

Além dos dados de acesso ao ensino básico, a PNAD-Contínua (2018) evidencia que cerca de $6,8 \%$ da população nacional com mais de 15 anos é analfabeta, ou seja, aproximadamente 11,3 milhões de analfabetos. Nesse indicador, também há grande disparidade entre as regiões nordeste (13,9\%) e sudeste (3,5\%) do Brasil, respectivamente, a maior e menor taxa de analfabetismo do país. Foi considerada a faixa etária superior a 15 anos, pois este é o grupo etário que já teria condições de concluir o processo básico de escolarização. 
Outro fator alarmante se dá em relação à visão que os brasileiros têm em relação aos professores do ensino básico, segundo uma pesquisa realizada por uma das mais prestigiadas entidades dedicadas à melhoria da educação mundial, a Varkey Foundation (2018). Dentre os 35 países avaliados, o Brasil figura na última posição do ranking de prestígio de docentes. Nesta pesquisa, foram entrevistadas mil pessoas, entre 16 e 64 anos, em que os entrevistados foram questionados quanto à percepção de respeito dos alunos para com os professores e, como resultado, menos de 1 em cada 10 (9\%) brasileiros acham que os alunos respeitam os professores.

\section{- Absenteísmo e Evasão Universitária}

Segundo o estudo realizado por Souto-Maior et al. (2011), os alunos que possuíam uma maior quantidade de faltas apresentavam um rendimento acadêmico menor do que os alunos com maior frequência, bem como alunos do período matutino possuíam melhor rendimento do que os alunos do período noturno. Nogueira et al. (2013), em um estudo sobre os fatores que impactam o desempenho acadêmico, concluiu que, dentre várias variáveis, como idade, gênero, notas de ingresso no curso superior (ENEM e vestibulares), o fator 'faltas' foi o que representou o maior impacto no desempenho dos discentes analisados. Ainda segundo o autor, com a análise dos dados levantados, foi possível concluir que cada falta adicional que o discente incorre, há um decaimento de 1,14 pontos em média em sua nota, sendo esta a única variável relevante encontrada. Já Araújo et al. (2011) realizaram um estudo com mais de 7.000 estudantes, encontrando um resultado que foi contra o esperado pelos autores, em que constataram que o maior número de faltas impactou positivamente no desempenho acadêmico dos discentes e encontraram, como possível resposta a este resultado contraditório, que este fato poderia estar atrelado à oferta dos cursos exclusivamente noturnos.

Quanto à evasão universitária, Machado et al. (2005) destacam três fatores: (a) incerteza na escolha do curso, fortemente influenciada pela inexperiência e pouca idade do ingressante, o que ocasiona dúvidas e frustrações na escolha da graduação; (b) "falsa evasão", caracterizada pela mudança de curso ou de IES, muito influenciada pelo primeiro fator; (c) questões financeiras, muito comuns em grandes centros, em que 0 custo de vida é elevado, considerando que os cursos superiores de período integral impedem, na maioria das vezes, que o aluno trabalhe para custear os estudos.

Bardagi \& Hutz (2009) apontam que a evasão universitária chega até $50 \%$ do total de matrículas, principalmente, nos primeiros semestres dos cursos. Os autores ainda apontam que, nos casos de evasão em semestres mais avançados dos cursos, a decisão pela desistência foi majoritariamente impulsiva, principalmente, por conta da insatisfação de longo prazo e não por uma reopção de carreira dos desistentes.

Em relação à EP da UFPel, de acordo com os relatórios disponíveis no Sistema Integrado de Gestão Cobalto, disponibilizados pelo colegiado do curso, desde a primeira turma ingressante (2010/1) até o atual semestre (2019/2), que ainda não está finalizado, podemos contabilizar, ao longo destes 20 semestres do curso de EP, cerca de 371 saídas de alunos em caráter de abandono ou desistência do curso, o que representa uma média de 18,5 alunos por semestre. O levantamento ainda apresenta uma tendência de crescimento na taxa de evasão, como a Figura 2 ilustra.

Figura 2 - Evasão de discentes da EP da UFPel ao longo dos semestres.

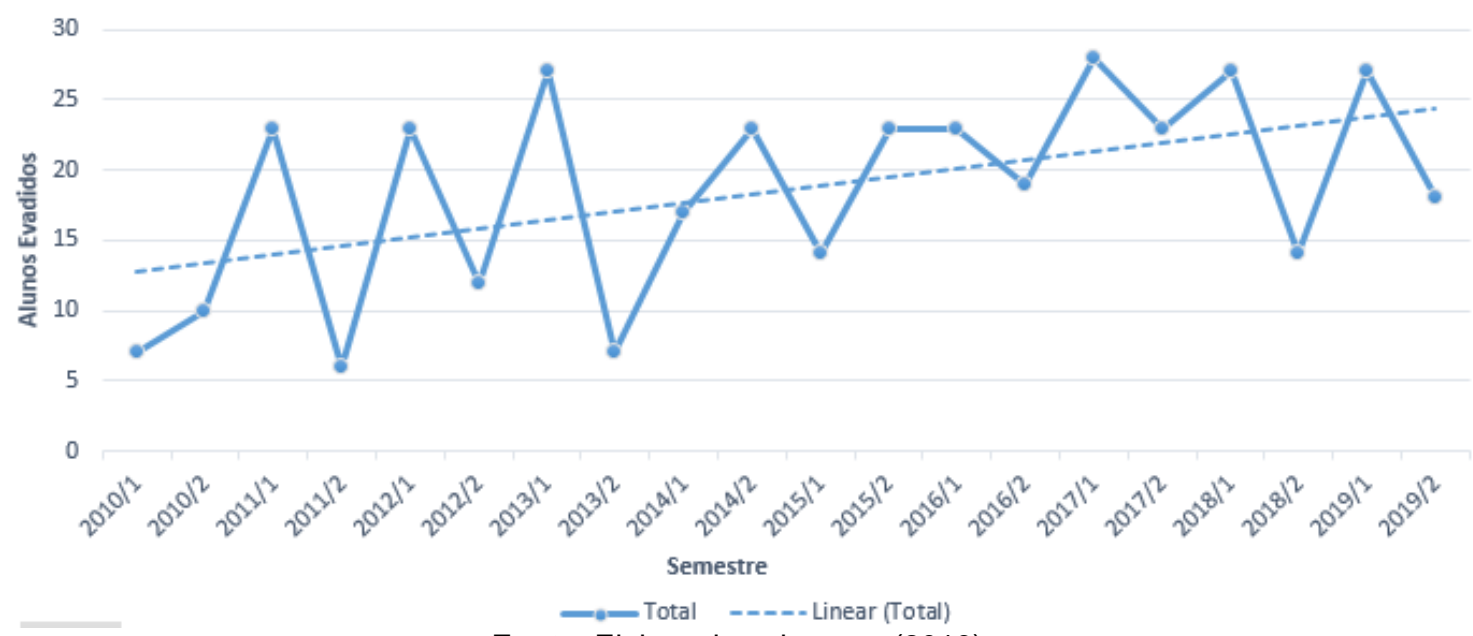

Fonte: Elaborado pelo autor (2019).

\section{- Atividade Remunerada}

Segundo um estudo realizado por Silva (2013), foi possível verificar que a relação entre atividade remunerada e a graduação traz uma probabilidade de fracasso no ensino superior $5,95 \%$ maior em 
comparação aos discentes que se dedicam, exclusivamente, aos estudos. Guimarães e Sampaio (2007) apontam que as possibilidades de ingresso, na Universidade, caem cerca de 3,7\% por hora adicional de trabalho, ou seja, após o ingresso na graduação, os discentes que mantêm essa responsabilidade têm seu desempenho acadêmico impactado em igual proporção, uma vez que mais horas de trabalho resultam em menos horas dedicadas para os estudos.

Em outro estudo realizado por Araújo et al. (2011), é apontado que boa parte dos alunos dos cursos noturnos trabalham durante o dia para poder custear seus estudos, o que acarreta em um número maior de faltas, porém por motivos justificáveis, ao exemplo de motivos profissionais. Este perfil de discente ainda apresentava um empenho maior nos estudos, bem como possuíam maior responsabilidade e interesse em recuperar o conteúdo perdido pelas faltas. Os autores ainda ressaltam que esses alunos trabalhadores possuem uma maior facilidade em absorver os conhecimentos, principalmente, pelo fato de poderem colocar em prática o conteúdo aprendido em sala de aula.

\section{METODOLOGIA}

A metodologia aplicada, neste estudo, se deu através da pesquisa de sites, artigos, livros e estudos nacionais e internacionais relacionados ao desempenho acadêmico, à gestão de desempenho e à gestão estratégica, de forma a nortear e basear o desenvolvimento da pesquisa. $O$ estudo foi dividido em quatro etapas: (1) estudo bibliográfico, (2) análise do ambiente, (3) análise dos dados e (4) proposição de soluções.

Para a coleta dos dados, os autores elaboraram um questionário que foi aplicado aos discentes da engenharia de produção da UFPel, sendo um questionário fechado de quinze questões, utilizando-se da escala Likert, tradicional de 5 pontos, para melhor mensuração e padronização dos dados. $O$ questionário consta, ao final do estudo, junto aos Apêndices. Essas questões serviram para a classificação do perfil de trabalho de cada discente, bem como a avaliação da autopercepção dos mesmos quanto ao seu desempenho acadêmico.

Quanto à análise dos dados, foi realizado o tratamento estatístico dos mesmos e, posteriormente, a padronização dos tipos de questões empregadas no estudo, bem como a segregação dos perfis de trabalho dos estudantes, cruzando os dados de forma a mensurar o índice de criticidade das questões para cada subdivisão de discentes de acordo com o tempo dedicado ao trabalho (dedicação exclusiva aos estudos, estagiário ou período integral).

\subsection{Caracterização da Pesquisa}

Tendo em vista os objetivos almejados, a pesquisa foi realizada com uma natureza descritiva e exploratória. Segundo Gil (2008), esta combinação da natureza exploratória e descritiva nos permite um maior conhecimento da teoria, o que nos leva a uma maior afinidade com o problema, bem como nos permite descrever o comportamento e a característica de um grupo, desde que sejam utilizados padrões na coleta dos dados. Porém, ressalta-se que a pesquisa não analisou medidas objetivas do desempenho acadêmico. Por este motivo, a percepção do desempenho pode se distinguir caso outras medidas de desempenho sejam empregadas.

O desdobramento da teoria, baseada na bibliografia, desenvolve-se em um estudo de caso, aplicado no curso em questão. De acordo com Gil (2008), a bibliografia atua como suporte, fornecendo o conteúdo para o estudo de caso, sendo composto por uma série de objetivos, no intuito do aprofundamento do tema proposto.

\subsection{Definição da Amostra}

O público-alvo do estudo são os discentes que exercem atividade remunerada em tempo integral ou parcial. Desses, derivará a amostragem necessária para a análise, fornecendo os dados para avaliação de desempenho.

Não existe um levantamento prévio da quantidade de alunos da EP que trabalham, bem como este número tende a ser muito volátil devido a fatores externos à Universidade. Portanto, o tamanho da amostra considerou o número total de discentes matriculados no curso de EP, que, no início do ano de 2020, contava com 200 alunos, segundo informações obtidas junto ao colegiado do curso.

O nível de confiança desejado é de $95 \%$ e erro amostral de $5 \%$, ou seja, considerando que o cálculo será aplicado a uma quantidade finita, sendo que, ao se utilizar da equação para populações fechadas, encontrou-se um total de 132 amostras necessárias conforme ilustrado na Equação 1 utilizada para população fechada ou finita. 


$$
n=\frac{\left\{\frac{\left[Z^{2} p(1-p)\right]}{E^{2}}\right\}}{\left\{1+\frac{\left.Z^{2} p(1-p)\right]}{E^{2} N}\right\}} \quad \text { Equação (1) }
$$

Fonte: Bussab e Morettin (2017)

Na equação 1, o z é o desvio padrão de proporção da mediana, para $95 \%$ de confiança, em que o mesmo representa $Z=1,96$; o $p$ significa o grau de confiança estimado $(p=0,95)$, $E$ é utilizado para representar o Erro Amostral $(0,05)$ e, por fim, $N$ é o valor da População Total $(N=200)$.

\section{ANÁLISE DOS RESULTADOS}

O questionário para a avaliação do Impacto da Atividade Remunerada no Desempenho Acadêmico dos discentes foi aplicado por meios eletrônicos, utilizando-se de plataformas on-line para divulgação.

Aaker (2007), em seu estudo sobre pesquisas de marketing, ressaltou algumas vantagens da coleta de dados por plataformas digitais, como a agilidade na troca de informações entre o pesquisador e seu público-alvo, bem como o maior conforto e comodidade propiciados ao entrevistado, uma vez que o mesmo pode responder a qualquer momento e local.

\subsection{Amostras}

A coleta das amostras totalizou 134 respondentes (67\% da população total). O período de apuração das coletas se estendeu um pouco além do esperado, dado o cenário pandêmico do início do ano de 2020 , sendo que muitos alunos estavam inacessíveis. O estado de pandemia foi instaurado durante a elaboração do estudo e, por esse motivo, foi incluída uma pergunta facultativa, a partir da qual o respondente que trabalha é questionado quanto ao impacto da pandemia em seu trabalho, se não houve impacto direto ou se o mesmo perdeu ou trocou de emprego.

A amostra foi dividida em um primeiro momento em dois grupos, representando os discentes que trabalham e os que não estão trabalhando. Posteriormente, a parcela de respondentes que trabalham foi subdividida em dois grupos: os que possuem uma jornada de trabalho integral e os que possuem uma jornada de meio período, como estagiários. A escolha de agrupar as amostras, nestes grupos, foi escolhida para possibilitar uma melhor análise dos dados e, assim, descobrir como cada grupo percebe o impacto do trabalho no seu rendimento acadêmico. O agrupamento das amostras resultou em três subgrupos de alunos: os que não estão trabalhando, 43 discentes; estagiários, 17 discentes e; trabalho em período integral, 74 discentes.

Quanto à pandemia, 22 dos $134(16,42 \%)$ reportaram estar trabalhando no início da pandemia e afirmaram que tiveram seu trabalho impactado direta e grandemente pela mesma. Ressalta-se que foram considerados apenas os maiores impactos, ou seja, os que tiveram uma grande alteração ou até a extinção da atividade laboral do discente (troca ou perda de emprego durante a pandemia, tendo a mesma como fator motivador da mudança). Dos 22 discentes impactados, 12 perderam o emprego, enquanto os outros 10 trocaram de emprego por conta da pandemia.

As demais questões são as contempladas com a escala Likert, em que os alunos responderam de acordo com o nível de concordância com a afirmação apresentada. As questões numeradas do questionário tiveram as respostas dos alunos divididas de acordo com as figuras a seguir.

\subsection{Análise dos Dados}

Primeiramente, foi realizada a mensuração dos indicadores gerais, considerando todos os respondentes, independentemente de estarem exercendo atividade remunerada ou não. Após, as amostras foram divididas em dois grupos: os empregados e os que se dedicam, exclusivamente, aos estudos. Por fim, o grupo de discentes empregados foi subdividido entre os que trabalham em período integral e os que são estagiários.

As questões numeradas, aplicadas através da escala Likert, podem ser subdivididas em dois grupos. Dez das quinze questões têm suas respostas consideradas como: quanto maior, melhor para o desempenho. Já as cinco questões restantes podem ter suas respostas classificadas, tais como: quanto maior, pior para o rendimento acadêmico. Esses dois tipos de afirmações foram apresentados em ordem aleatória no questionário, com a intenção de evitar a tendência de respostas e possibilitar a obtenção de dados verossímeis.

Os gráficos com o resultado das análises descritivas dos dados para cada um dos três estratos amostrais são apresentados no Apêndice 3 .

No intuito de valorar os índices, foi realizada uma média aritmética simples, somando-se os algarismos representantes das respostas e dividindo-os pela quantidade de respostas fornecidas no questionário, chegando, dessa maneira, ao Índice Likert Médio (ILM) de cada questão do questionário. Com o objetivo de 
ilustrar os resultados de forma qualitativa e de fácil entendimento, foi elaborado um quadro com os resultados representados em percentual, representando a aderência dos respondentes a cada afirmação do questionário. Para a conversão do Indice Likert Médio para o percentual de aderência, o intervalo de 1 a 5 aplicado no questionário foi representado em uma escala de $0 \%$ a $100 \%$.

No sentido de ordenar cada questão, de acordo com o grau de criticidade encontrado, independentemente do tipo de afirmação (maior - melhor ou maior - pior), para as questões do tipo maior melhor foram considerados os valores faltantes para o resultado ideal de $100 \%$ na afirmação, ou seja, onde o índice encontrado foi de $60 \%$ originalmente, subtrai-se o valor encontrado de 1, encontrando, assim, $40 \%$ de criticidade para a afirmação.

\subsubsection{Análise de Indicadores por Grupos}

Para uma maior acuracidade das análises, fez-se necessária a análise individual por grupo de estudo, uma vez que a análise geral pode tender a um dos grupos. As amostras foram agrupadas de acordo com a situação do discente em relação ao mercado de trabalho, separados entre os que trabalham e os que estão se dedicando, exclusivamente, aos estudos. Posteriormente, o grupo de discentes que está trabalhando foi subdividido entre os que estão estagiando e os que estão com vínculo empregatício em funções de período integral. Dessa forma, foi possível verificar o impacto de cada afirmação sobre os diferentes níveis de disponibilidade de tempo aos estudos que cada grupo de discentes possui para a dedicação acadêmica. Assim, foi possível mensurar os dados de forma a encontrar as principais questões que afetam cada grupo de discentes estudado.

Foi possível verificar que cinco questões têm maior relevância, independente do grupo de estudo, sendo estas as questões:

- Q12: As atividades e trabalhos demandam muito tempo para serem realizadas.

- Q14: A Universidade e o trabalho impactam um ao outro. Dessa forma, não consigo atingir meu melhor desempenho (em ambos).

- Q4: Em período de avaliação, preciso faltar às aulas para estudar.

- Q8: Procuro resumos ou estudo apenas o que parece ser mais importante.

- Q13: Todo semestre fico em exame ao menos em uma disciplina.

Percebeu-se que, quanto menor o tempo disponível aos estudos, maior o nível de criticidade dessas questões. Verificou-se, ainda, o grupo de estudantes que não exercem atividade remunerada e apontaramse as mesmas afirmações que o grupo de discentes que exercem atividade laboral apesar de este grupo representar apenas $32,09 \%$ da amostra total.

O grupo de discentes que se dedicam, exclusivamente, aos estudos, é a segunda maior parcela de respondentes, com 43 das 134 respostas do estudo, representando 32,09\% das respostas do questionário. Para esse grupo, não houve nenhuma questão classificada com o nível CRÍTICO (81 a 100\% de criticidade), porém houve quatro questões classificadas com nível de criticidade ALTO (61 à 80\%), na ordem decrescente de importância: a Q4 (necessidade de faltar às aulas para estudar) e a Q12 (duração de atividades e trabalhos), ambas com 69,30\% de criticidade e; a Q8 (estudo apenas por meio de resumos) e a Q14 (impacto do Trabalho na Universidade e vice-versa), ambas com $65,12 \%$ de criticidade. Com nível de criticidade considerado MÉDIO, foi apontada apenas a Q13 (ao menos, um exame por semestre), com 53,02\%.

Os alunos que estagiam representaram a menor parcela de respondentes, das 134 respostas obtidas, apenas 17 eram de estagiários, ou seja, apenas 12,69\% do total. Este grupo apresentou 9 questões com índices de nível MÉDIO (41 à 60\%) ou superior, sendo, ao menos, uma questão considerada com o nível CRÍTICO (81 à 100\%): a Q12 (duração de atividades e trabalhos) com 81,18\%. Com o nível considerado ALTO (61 à 80\%), foram 4 questões: a Q4 (necessidade de faltar às aulas para estudar), com $74,12 \%$, a Q14 (impacto do Trabalho na Universidade e vice-versa), com 68,23\%, a Q8 (estudo apenas por meio de resumos) com $64,70 \%$ e a Q13 (ao menos, um exame por semestre), com 62,35\%. As consideradas com nível MÉDIO (41 à 60\%) entre os estagiários foram as questões: Q5 (estudo apenas às vésperas de avaliações), Q10 (possibilidade de frequentar a Universidade em horários extraclasse), Q6 (concentração e entendimento durante as aulas) e Q11 (tempo disponível para execução das atividades com qualidade). Para esse grupo, o gargalo de desempenho é o tempo necessário para a execução das atividades e trabalhos extraclasse, seguido pela necessidade de faltar a algumas aulas para estudar para outras avaliações, bem como é apontado, em terceiro lugar, o impacto do trabalho na Universidade e vice-versa, impossibilitando atingir melhor desempenho do discente em ambas as funções (trabalho e academia).

Já os discentes pertencentes ao grupo de alunos que trabalham em período integral representam a maior parcela dos respondentes, com um total de 74 de 134 respostas, ou seja, $55,22 \%$ da amostra total. Este grupo apontou ao menos 8 questões com os níveis iguais ou acima de MÉDIO (41 a 60\%), em que apontaram como CRÍTICO (81 a 100\%), apenas uma questão: a Q12 (duração de atividades e trabalhos), com 82,70\%. Com nível ALTO (61 a 80\%), foram apontadas 5 questões, sendo: a Q14 (impacto do Trabalho 
na Universidade e vice-versa), com 79,46\%; a Q4 (necessidade de faltar às aulas para estudar), com 77,57\%; a Q8 (estudo apenas por meio de resumos), com 76,49\%, a Q10 (possibilidade de frequentar a Universidade em horários extraclasse), com $64,60 \%$ e a Q13 (ao menos, um exame por semestre), com $60,54 \%$. As questões consideradas um pouco menos críticas, com o nível MÉDIO (41 à 60\%), foram duas: a Q11 (tempo disponível para execução das atividades com qualidade), com 59,46\% e a Q5 (estudo apenas às vésperas de avaliações), com $44,60 \%$ de criticidade.

\section{DISCUSSÕES}

Percebe-se que os dois grupos, bem como os subgrupos, apresentaram um padrão similar em suas respostas. Foram apontados os mesmos fatores como os mais críticos, sendo aqueles que demandam mais tempo extraclasse, como o tempo necessário para a execução das atividades e trabalhos ou a necessidade de faltar a algumas aulas para estudar em períodos de avaliações. Também, foi observada a percepção de comprometimento do rendimento global (nos casos dos alunos que trabalham e estudam) apontado pelos respondentes: os mesmos não conseguem atingir seus melhores resultados e o trabalho e a Universidade impactam um no desempenho do outro.

Através da conversão do ILM obtido na Q15 (qual a média das notas obtidas pelo aluno), pode-se obter uma estimativa média das notas dos discentes por grupo. Com isso, percebe-se que a média de notas é maior no grupo de alunos que não estão trabalhando, no momento, em relação ao grupo de discentes que desempenham atividades laborais (meio período ou período integral). Enquanto o grupo que não está trabalhando apresentou uma média de 4,093 no ILM (equivalente à uma nota média de 8,19 de 10), o grupo que desempenha alguma atividade laboral apresentou uma média de 3,835 no ILM (equivalente a uma nota média de 7,7 de 10). Porém, mesmo com esta redução na média das notas, os discentes que trabalham em período integral apresentaram uma média de notas superior à dos discentes que estagiam. $O$ grupo que trabalha em período integral apresentou uma média de 3,8648 no ILM (equivalente a uma nota média de 7,73 de 10), e o grupo que estagia apresentou uma média de 3,7058 no ILM (equivalente a uma nota média de 7,41 de 10).

O fato de a média de notas ser maior no grupo de alunos que não trabalha é reforçado pelos resultados obtidos com a Q13 (aluno fica em, ao menos, um exame por semestre). Esta questão foi uma das que mais apresentou disparidade entre os grupos de discentes, pois, enquanto o grupo de alunos que se dedica exclusivamente aos estudos apontou um nível de criticidade médio de 53,02\% (nível MÉDIO), o grupo de alunos que exerce atividade laboral (meio período ou período integral) apresentou uma média de 60,88\% (ALTO) no nível de criticidade. Na Q13, assim como na Q15, o subgrupo de alunos que trabalham em período integral também apresentou um desempenho levemente superior aos alunos que trabalham em meio período. Com relação aos discentes que trabalham integralmente, apontou um nível de criticidade médio de $60,54 \%$ (ALTO), enquanto o grupo de estagiários apontou uma média de 62,35\% (ALTO) neste mesmo índice.

A questão que obteve o maior nível de criticidade do questionário aplicado, em todos os grupos e subgrupos, foi a Q12 (tempo necessário para a realização de atividades e de trabalhos extraclasse). Houve uma concordância entre os grupos, em que esta questão aparece como o principal gargalo no desempenho dos discentes. É possível perceber, ainda, um crescimento neste índice inversamente proporcional ao tempo hábil que cada grupo de discentes possui. Em outras palavras, quanto mais tempo é despendido em atividades laborais, maior o nível crítico considerado pelos discentes. Para o grupo que não trabalha, o nível de criticidade encontrado foi de $69,30 \%$ (ALTO), enquanto o grupo de alunos estagiários apontou um percentual de $81,18 \%$ (CRÍTICO), e o grupo de discentes que trabalham em período integral apontou este índice como CRÍTICO também, com uma média de $81,70 \%$ de criticidade. Ou seja, de acordo com a autopercepção dos discentes, o tempo exigido para a elaboração de atividades e trabalhos extraclasse é o principal gargalo de desempenho dos mesmos.

Um fator interessante levantado pelos resultados diz respeito à disponibilidade e/ou possibilidade dos discentes quanto à frequência na Universidade em horários que não sejam os de aula, ou seja, em atividades acadêmicas extraclasse dentro da própria Universidade. Na Q10 (se os alunos conseguem ir à Universidade para consulta de professores, monitoria, vistas de provas etc.), o grupo que apresentou maior disponibilidade para frequentar a Universidade, em horários inversos às aulas, foi o grupo de alunos que estagiam. Este grupo apontou um nível de criticidade de, apenas, 48,24\% (MÉDIO), enquanto o grupo de alunos que não trabalham apontou uma média de $61,54 \%$ (ALTO) de criticidade, e o grupo que trabalha integralmente apontou um percentual $64,60 \%$ (ALTO) para este mesmo índice. O resultado deste índice pode indicar um maior aproveitamento da infraestrutura e das ferramentas disponibilizadas pela Universidade por parte dos alunos que estagiam. Vale ressaltar que o estágio obrigatório é uma disciplina obrigatória, em que se faz necessária a visita do aluno à Universidade fora dos horários de aula, uma vez que este componente curricular não possui créditos presenciais e necessita da elaboração e entrega de relatório de estágio, o que pode contribuir para uma maior presença de alunos estagiários nas dependências da Universidade em horários diversos. A Figura 3 representa um resumo das respostas das principais questões, por grupo de discentes. 
Figura 3 - Resumo das principais questões

\begin{tabular}{|c|cc|cc|cc|}
\hline \multirow{2}{*}{ QUESTÃO } & \multicolumn{5}{|c|}{ GRUPO DE DISCENTES } \\
\cline { 2 - 7 } & $\begin{array}{c}\text { TRABALHO EM } \\
\text { PERIODO INTEGRAL }\end{array}$ & ESTAGIÁRIOS & NÄO TRABALHAM \\
\cline { 2 - 7 } & $\%$ & Criticidade & $\%$ & Criticidade & $\%$ & Criticidade \\
\hline $\mathbf{1 2}$ & 82,70 & CRITICO & 81,18 & CRITICO & 69,30 & ALTO \\
\hline $\mathbf{1 4}$ & 79,46 & ALTO & 74,12 & ALTO & 65,12 & ALTO \\
\hline $\mathbf{4}$ & 77,57 & ALTO & 68,23 & ALTO & 69,30 & ALTO \\
\hline $\mathbf{8}$ & 76,49 & ALTO & 64,70 & ALTO & 65,12 & ALTO \\
\hline $\mathbf{1 0}$ & 64,60 & ALTO & 48,24 & MÉDIO & 34,42 & BAIXO \\
\hline $\mathbf{1 3}$ & 60,54 & ALTO & 62,35 & ALTO & 53,02 & MÉDIO \\
\hline $\mathbf{1 1}$ & 59,46 & MÉDIO & 42,35 & MÉDIO & 34,88 & BAIXO \\
\hline $\mathbf{5}$ & 44,60 & MÉDIO & 48,24 & MÉDIO & 39,07 & BAIXO \\
\hline
\end{tabular}

Fonte: Elaborado pelos autores (2020).

\subsection{Melhorias propostas}

O ponto indicado como gargalo pelos três grupos de discentes foi a questão do tempo necessário para a elaboração de atividades e trabalhos extraclasse. Este ponto foi abordado como o principal pela escala Likert e pelas sugestões que os alunos deixaram no campo de sugestões. Os discentes que apresentaram sugestões também trabalham em período integral e, em sua maioria, sugeriram a substituição das atividades extraclasse por atividades em aula, com mais exercícios e mais direcionadas. Outro ponto levantado por esses discentes foi a questão de não ser possível realizar trabalhos de campo em empresas ou setores que não são os de atuação do discente. Em outras palavras, a impossibilidade de se deslocar entre empresas ou até mesmo entre setores da empresa que os emprega para pesquisas e levantamento de dados. Nesse sentido, essas atividades poderiam ser substituídas ou diluídas em sala de aula, sendo que o discente já tem o compromisso firmado de comparecer dentro do turno letivo. A opção de estudo de empresas e setores de forma remota, por gravações ou dados públicos, sem que seja obrigatória a presença do aluno nestes postos, também foi identificada, uma vez que os horários de trabalho do aluno e da empresa ou setor estudado tendem a colidir, inviabilizando a presença do discente que trabalha.

Outro ponto apontado pelos alunos no campo de sugestões, que obteve resultados relevantes no índice de criticidade, foi a impossibilidade de frequência dos discentes na Universidade em horários que não os de aula. Sobre este ponto, no campo de sugestões, foi apontado por, ao menos dois alunos, o sentimento de estar em desvantagem frente aos demais por não poder usufruir da infraestrutura da UFPel em horários que não os de aula. Esses alunos se queixaram da falta de ofertas de disciplinas optativas no período noturno, sendo que não é possível realizá-las se o aluno estiver em seu semestre regular e sem reprovações e, que mesmo quando há lacunas em seus horários, não há oferta de disciplinas optativas no turno noturno. Por conta da carga horária do curso e das disciplinas obrigatórias, a atuação, neste ponto, pode se provar limitada. Porém, uma forma de mitigar esse sentimento dos discentes pode ser a ampliação das ofertas de disciplinas optativas em horários que antecedem às aulas, entre às $17 \mathrm{~h}$ e $18 \mathrm{~h} 50 \mathrm{~min}$. Este horário possibilitaria a mais alguns discentes que trabalham participar das aulas.

O terceiro ponto em comum entre os grupos de discentes foi a percepção de que a Universidade e o trabalho, quando executados em conjunto, impactam negativamente um ao outro, impossibilitando o discente de atingir seu melhor desempenho em ambos. De fato, quanto maior o tempo despendido em uma atividade, menor o tempo disponível para a execução da outra, dada a quantidade de horas de um dia. Porém, pode ser possível realizar junções ou menções de uma atividade na outra, de forma que a sensação do aluno seja a de estar sempre desempenhando a função de aprender e trabalhar, sem que haja uma delimitação tão grande entre o horário de trabalho e de estudo, o que, por vezes, pode causar a sensação de cansaço e diminuir a atenção do aluno na atividade seguinte. Nesse sentido, pode ser possível integrar mais o trabalho dos alunos com as atividades acadêmicas, através de exemplos de aplicabilidade prática dos conhecimentos da Engenharia de Produção no mercado de trabalho, haja vista que o leque de conhecimentos e habilidades de um engenheiro de produção é extremamente amplo e, por vezes, falta aprofundamento prático em alguns temas. Ao menos dois alunos sugeriram um maior direcionamento nas aulas, com mais exemplos práticos e 
de cursos extraclasse que ajudem na identificação do aluno com uma área de maior afinidade, dentro da vasta área de atuação da EP.

No geral, pôde-se perceber que as questões aplicadas no questionário têm relevância similar para todos os discentes, pois os alunos tendem a ter uma constância em suas respostas, o que independe de sua posição no mercado de trabalho. Em outras palavras, a atuação para melhoria em quatro ou cinco questões pode acarretar uma melhoria considerável na autopercepção de desempenho dos três grupos de alunos, o que, por sua vez, poderá aumentar a satisfação geral do indivíduo quanto a sua condição de aluno universitário.

\section{CONCLUSÕES}

Dada a crescente demanda por profissionais multifacetados e indivíduos polivalentes, bem como a necessidade de trabalhar em paralelo aos estudos, configura-se a necessidade de vários discentes conciliar o trabalho e a graduação, levando a uma diminuição no desempenho dos mesmos em ambas as tarefas (estudar e trabalhar). Com isso, as motivações deste estudo se provaram verdadeiras, uma vez que foi possível comprovar que os discentes enxergam uma boa margem de melhoria em seu desempenho acadêmico no tocante a questões que esbarram com as laborais e, sendo possível melhorar a autopercepção dos alunos quanto ao desempenho através de ações simples e eficazes.

Foi realizada a segregação dos dados, de maneira proposital, de acordo com a situação dos alunos frente ao mercado de trabalho, bem como a análise individual dos índices por grupo. Foi possível encontrar pontos em comum para melhoria do desempenho geral dos alunos do curso de EP, haja vista que ao menos cinco questões foram apontadas como elo em comum entre os três grupos de discentes.

Por outro lado, vale ressaltar o fato do estado pandêmico global e dos efeitos da pandemia que se instalaram no decorrer da elaboração deste estudo e acabou impactando na aplicação do mesmo. Percebeuse que seria possível uma maior quantidade de respondentes e, de forma mais ágil, caso não estivéssemos passando por esse estado de exceção. Além dos impactos no estudo, a pandemia impactou de uma forma direta os discentes que trabalhavam, sendo responsável pela perda do emprego de, ao menos, 12 dos 134 respondentes ( $8,9 \%$ do total de respondentes).

Ressalta-se, ainda, o fato de que 108 dos 134 (80,6\%) respondentes afirmaram que não houve impacto da pandemia, para quem ainda estava em fases iniciais, em seu trabalho. Este percentual também engloba os alunos que não trabalhavam antes do início da pandemia, caracterizados pelos respondentes que afirmaram não estar trabalhando e, simultaneamente, responderam que não sofreram impacto da pandemia, ou seja, não estavam desempregados por conta da pandemia, mas sim por outros motivos.

Mesmo com os impactos da pandemia, o grupo de alunos que exercem atividade laboral ainda é o que representou maior percentual dentre os respondentes (55,22\%). Esse fato pode significar uma maior procura do curso de EP por parte dos alunos que já trabalham, talvez, por ser a única engenharia noturna. Também, pode significar uma maior colocação profissional para os alunos de engenharia de produção, haja vista que mais da metade está inserido no mercado de trabalho, e exercem atividades laborais de período integral.

A pesquisa não analisou comparativamente medidas objetivas do desempenho acadêmico. Por isso, a percepção do desempenho pode se distinguir caso outras medidas de desempenho sejam empregadas. Indicamos como possibilidade de trabalhos futuros estudos comparativos de medidas objetivas de desempenho acadêmico.

\section{REFERÊNCIAS}

AAKER, D. A.; et al. Pesquisa de marketing. 2ª ed. São Paulo: Atlas, 2007.

AGÊNCIA IBGE. PNAD Contínua 2018: educação avança no país, mas desigualdades raciais e por região persistem. Disponível em: <https://agenciadenoticias.ibge.gov.br/agencia-sala-de-imprensa/2013-agencia-de-noticias/ releases/24857-pnad-continua-2018-educacao-avanca-no-pais-mas-desigualdades-raciais-e-por-regiao-persistem> . Acesso em 16 nov. 2019.

AGUINIS, H. Performance Management. 3르 ed. Nova Jersey: Pearson Prentice Hall, 2013.

ALDAY, H. E. C. Planejamento Estratégico Dentro do Conceito de Administração Estratégica. Revista FAE, Curitiba, v. 3, n.2, p.9-16, ago. 2000.

ARAÚJO, E. A. T.; et al. Desempenho Acadêmico de Discentes do Curso de Ciências Contábeis: Uma Análise dos Seus Fatores Determinantes em uma IES Privada. In: XXXV ENCONTRO DA ANPAD. Rio de Janeiro. Set. 2011.

BARDAGI, M. P.; HUTZ, C. S. "Não havia outra saída": percepções de alunos evadidos sobre o abandono do curso superior. Psico-USF (Impr.), Itatiba, v. 14, ํㅜ 1. Abr. 2009.

BARROSO, P. F. Relação da taxa de escolaridade com os indicadores de emprego e desemprego. Conversas e controvérsias, Porto Alegre, v. 1, n. 1, p. 31-39. 2010. 
BRANDÃO, H. P.; GUIMARÃES, T. A. Gestão de Competências e Gestão de Desempenho: Tecnologias Distintas ou Instrumentos de um Mesmo Construto? Revista de Administração de Empresas, São Paulo, v. 41, n. 1, p. 8-15. Mar. 2001.

BUSSAB, W. O.; MORETTIN, P. A. Estatística Básica. 9ª ed. Saraivauni, 2017.

CHANDLER, A. D. Strategy and Structures. Cambridge: MIT, 1962.

CORNACHIONE, E. B. et al. O bom é meu, o ruim é seu: perspectivas da teoria da atribuição sobre o desempenho acadêmico de alunos da graduação em Ciências Contábeis. Revista Contabilidade \& Finanças, USP, São Paulo, v. 21, n. 53, p. 1-24, ago. 2010

DIRETORIA DE ESTATíSTICAS EDUCACIONAIS, DEED. Censo da Educação Superior 2018. Brasília, DF, INEP/MEC, 2019.

EDUCA IBGE. Pirâmide Etária: Educação. Disponível em: <https://educa.ibge.gov.br/jovens/conheca-o-brasil/ populacao/18317-educacao.html>. Acesso em 17 nov. 2019.

FERRETTI, J. C.; MADEIRA, F. R. Educação/Trabalho: reinventando o passado. Cadernos de Pesquisa. São Paulo, no 80, pp. 75-86. Fev. 1992.

FONSECA, C. J. C. TAO: Terminologia do Aprimoramento Organizacional. Rio de Janeiro: Qualitymark, 1997.

G1. Brasil cai para último lugar no ranking de status do professor. Disponível em: <https://g1.globo.com/ educacao/noticia/2018/11/08/brasil-cai-para-ultimo-lugar-no-ranking-de-status-do-professor.ghtml>. Acesso em 17 nov. 2019.

GAUTÉRIO, E. G., MATTOS, V. L. D. Utilização do Controle Estatístico de Processo na Avaliação de Desempenho Acadêmico. Revista Produção Online, Florianópolis, SC, v.14, n. 2, p. 744-763, abr./jun. 2014.

GIL, A. C. Como Elaborar Projetos de Pesquisa. 4ª ed. São Paulo: Atlas, 2008.

GUIMARÃES, J.; SAMPAIO, B. The influence of family background and individual characteristics on entrance tests scores of Brazilian university students. In: XII Encontro Regional de Economia. Fortaleza. Jul. 2007.

HRONEC, S. M. Sinais vitais: usando medidas de desempenho da qualidade, tempo e custo para traçar a rota para o futuro de sua empresa. São Paulo: Makron Books, 1994. 256p.

INDEX MUNDI. Dados Históricos - Taxa de Desemprego Brasil. Disponível em: <https://www.indexmundi.com/g/ g.aspx?v=74\&c=br\&l=pt>. Acesso em 20 out. 2019.

INSTITUTO DE PESQUISA ECONÔMICA APLICADA, IPEA. Mercado de Trabalho. Disponível em: <http://www.ipea.gov.br/cartadeconjuntura/index.php/tag/taxa-de-desemprego/>. Acesso em 05 out. 2019.

JENSEN J. A.; SAGE, P. A. A Systems Management Approach for Improvement of Organizational Performance Measurement Systems. Information Knowledge Systems Management, v. 2, no 1, 33-61p, 2000.

MACHADO, S. P.; MELO FILHO, J. M.; Pinto, A. C. A evasão nos cursos de graduação de química: uma experiência de sucesso feita no Instituto de Química da UFRJ para diminuir a evasão. São Paulo: Química Nova, 28, S41-S43. Dez. 2005.

MAGALHÃES, E. A. et al. Custo do ensino de graduação em instituições federais de ensino superior: o caso da Universidade Federal de Viçosa. Revista de Administração Pública — RAP — Rio de Janeiro 44(3):637-66, maio/jun. 2010.

MARÇAL, C. A. M. A avaliação de desempenho empresarial: o passo seguinte à implementação do sistema de gestão. (Dissertação de Mestrado em Gestão Empresarial) - Fundação Getúlio Vargas, Rio de Janeiro, 2008.

MIRANDA, G. J. et al. Determinantes do desempenho acadêmico na área de negócios. In: IV EnEPQ. Brasília. Nov. 2013.

MUNHOZ, A. M. H. Uma análise multidimensional da relação entre inteligência e desempenho acadêmico em universitários ingressantes. (Tese de doutorado) - Faculdade de Educação da Universidade Estadual de Campinas, Campinas, 2004.

NOGUEIRA, D. R.; et al. Fatores que impactam o Desempenho Acadêmico: Uma Análise com Discentes do Curso de Ciências Contábeis no Ensino Presencial. Revista de Informação Contábil. Pernambuco, v. 7, n. 3, p. 51-62, set. 2013.

SANTOS, N. A. Determinantes do desempenho acadêmico dos Alunos dos Cursos de Ciências Contábeis. (Tese de doutorado) - Universidade de São Paulo, São Paulo, 2012.

SILVA, R. F. Fatores que influenciam o desempenho acadêmico. São Paulo, 2013. 39 f. (Dissertação de Mestrado em Microeconomia Aplicada) - Insper Instituto de Ensino e Pesquisa, São Paulo, 2013.

SINK, D. S.; TUTTLE, T. C. Planning and Measurement in Your Organization of the Future. Georgia, Industrial Engineering and Management Press, 1989.

SOUTO-MAIOR, C. D.; et al. Análise dos Fatores que afetam o desempenho de alunos de graduação em administração e Contabilidade na disciplina de pesquisa operacional. In: XXXV ENCONTRO DA ANPAD. Rio de Janeiro. Set. 2011.

STURM, C. H., SCHRIPPE, P., MEDEIROS, F. S. B., KOSCHEK, J. F., WEISE, A. D. Mapeamento e análise de 
desempenho da graduação e da pós-graduação em Engenharia de Produção no Brasil. Gestão \& Produção, São Carlos, v. 22, n. 1, p. 149-163, 2015.

UNIVERSIDADE FEDERAL DE PELOTAS. Centro de Engenharias. Disponível em: <https://wp.ufpel.edu.br/ ceng/ceng/>. Acesso em: 16 nov. 2019.

WEICK, K. E. Educational organizations as loosely coupled systems. Administrative Science Quarterly, v. 21, p. 1-19, 1976. 


\section{Apêndices}

Apêndice 1 - Questionário aplicado

\section{AVALIAÇÃO DE DESEMPENHO ACADÊMICO}

Este questionário tem como objetivo a mensuração do Desempenho Acadêmico dos discentes do curso de Engenharia de Produção. Por favor, responda as perguntas avaliando os itens em 5 alternativas, ao qual: (1) para discordo totalmente, (2) para discordo parcialmente, (3) para não concordo nem discordo, (4) para concordo parcialmente e (5) para concordo totalmente.

É garantido o sigilo dos discentes, pois esta pesquisa tem um cunho quantitativo.

\section{Matrícula:}

\section{Atualmente está trabalhando? ( ) NÃO \\ ( ) SIM, estágio ( ) SIM, periodo integral}

Seu trabalho foi afetado pela pandemia?

\begin{tabular}{|c|c|c|}
\hline 01 & Durante a semana, em média, consigo ter 8 horas diárias de sono. & (1 a 5$)$ \\
\hline 02 & Não me atraso para as aulas. & (1 a 5$)$ \\
\hline 03 & Sempre saio ao término das aulas, não costumo sair mais cedo. & (1 a 5$)$ \\
\hline 04 & Em período de avaliação, preciso faltar às aulas, para estudar. & (1 a 5$)$ \\
\hline 05 & Estudo ao longo do semestre, não deixo para última hora. & (1 a 5$)$ \\
\hline 06 & Consigo me concentrar e entender tudo o que é ministrado em aula. & (1 a 5$)$ \\
\hline 07 & Estudo todo o conteúdo cobrado e faço meus próprios resumos. & (1 a 5$)$ \\
\hline 08 & Procuro resumos ou estudo apenas o que parece ser mais importante. & (1 a 5$)$ \\
\hline 09 & Costumo tomar nota durante as aulas e questionar quando tenho dúvidas. & $(1$ a 5$)$ \\
\hline 10 & $\begin{array}{l}\text { Quando necessário, consigo vir à Universidade em outros turnos (aulas, } \\
\text { professores, monitoria, vistas de provas, etc.). }\end{array}$ & $\begin{array}{l}\text { consultar } \\
(1 \text { a } 5)\end{array}$ \\
\hline 11 & $\begin{array}{l}\text { Possuo tempo suficiente para a realização das tarefas extraclasse e trabalh } \\
\text { qualidade esperada. }\end{array}$ & $\begin{array}{l}\text { os com a } \\
(1 \text { a } 5)\end{array}$ \\
\hline 12 & As atividades e trabalhos, demandam muito tempo para serem realizadas. & (1 a 5$)$ \\
\hline 13 & Todo semestre fico em exame ao menos em uma disciplina. & (1 a 5$)$ \\
\hline 14 & $\begin{array}{l}\text { A Universidade e o trabalho impactam um ao outro. Dessa forma, não consi } \\
\text { meu melhor desempenho (em ambos). }\end{array}$ & $\begin{array}{l}\text { go atingir } \\
(1 \text { a } 5)\end{array}$ \\
\hline 15 & $\begin{array}{l}\text { Utilize: } 1-(0 \text { a } 2) / 2-(3 \text { e } 4) / 3-(5 \text { e } 6) / 4-(7 \text { e } 8) / 5-(9 \text { e } 10) \\
\text { Minha média de notas fica em torno de: }\end{array}$ & (1 a 5$)$ \\
\hline
\end{tabular}

Fonte: Elaborado pelos autores (2020) 
Apêndice 2 - Classificação das afirmações

\begin{tabular}{|c|c|c|}
\hline \multicolumn{3}{|c|}{ GRUPOS DE QUESTÕES } \\
\hline $\mathbf{N}^{0}$ & AFIRMAÇĀO & TIPO \\
\hline 1 & Durante a semana, em média, consigo ter 8 horas diárias de sono. & \multirow{10}{*}{ 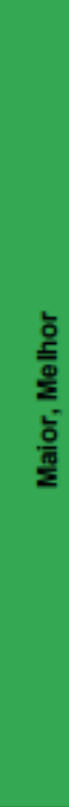 } \\
\hline 2 & Não me atraso para as aulas. & \\
\hline 3 & Sempre saio ao término das aulas, não costumo sair mais cedo. & \\
\hline 5 & Estudo ao longo do semestre, não deixo para última hora. & \\
\hline 6 & Consigo me concentrar e entender tudo o que é ministrado em aula. & \\
\hline 7 & Estudo todo o conteúdo cobrado e faço meus próprios resumos. & \\
\hline 9 & Costumo tomar nota durante as aulas e questionar quando tenho dúvidas. & \\
\hline 10 & $\begin{array}{l}\text { Quando necessário, consigo vir à Universidade em outros turnos (aulas, consultar } \\
\text { professores, monitoria, vistas de provas, etc). }\end{array}$ & \\
\hline 11 & $\begin{array}{l}\text { Possuo tempo suficiente para a realização das tarefas extraclasse e trabalhos com } \\
\text { a qualidade esperada. }\end{array}$ & \\
\hline 15 & $\begin{array}{l}\text { Utilize: } 1-(0 \text { a } 2) / 2-(3 \text { e } 4) / 3-(5 \text { e } 6) / 4-(7 \text { e } 8) / 5-(9 \text { e } 10) \text {. Minha média } \\
\text { de notas fica em torno de: }\end{array}$ & \\
\hline 4 & Em periodo de avaliações, preciso faltar às aulas, para estudar. & \multirow{5}{*}{$\begin{array}{l}\frac{2}{2} \\
\frac{0}{0} \\
\frac{0}{2}\end{array}$} \\
\hline 8 & Procuro resumos ou estudo apenas o que parece ser mais importante. & \\
\hline 12 & As atividades e trabalhos, demandam muito tempo para serem realizadas. & \\
\hline 13 & Todo semestre fico em exame ao menos em uma disciplina. & \\
\hline 14 & $\begin{array}{c}\text { A Universidade e o trabalho impactam um ao outro. Dessa forma, não consigo } \\
\text { atingir meu melhor desempenho (em ambos). }\end{array}$ & \\
\hline
\end{tabular}

Fonte: Elaborado pelos autores (2020)

Apêndice 3 - Gráficos da Análise Descritiva dos Dados

Figura 4 - Gráfico de respostas do grupo de estudantes que trabalham turno integral

Respostas dos Discentes que Trabalham Turno Integral

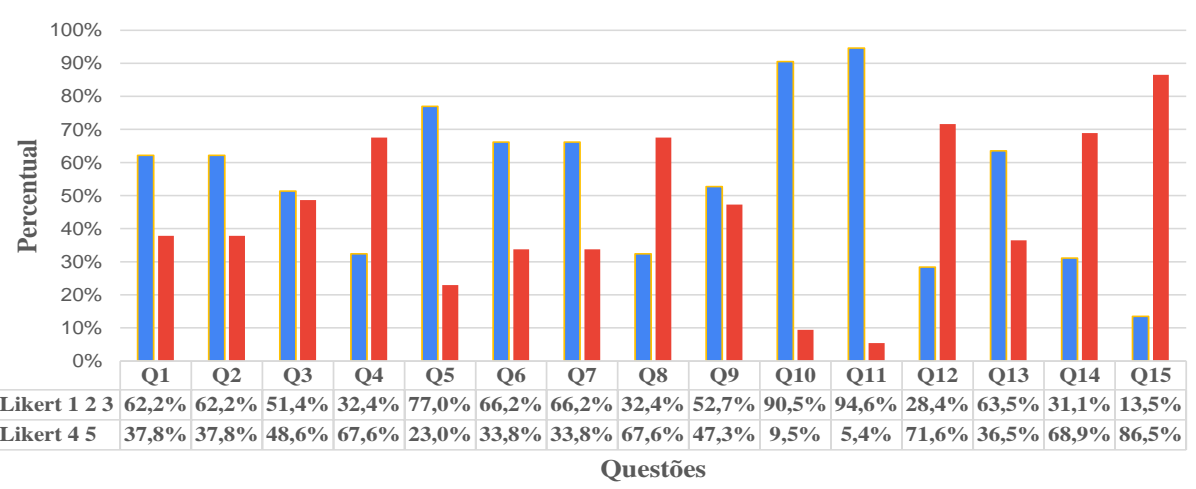

Fonte: Elaborado pelos autores (2020) 
Figura 5 - Gráfico de respostas do grupo de estudantes que estagiam

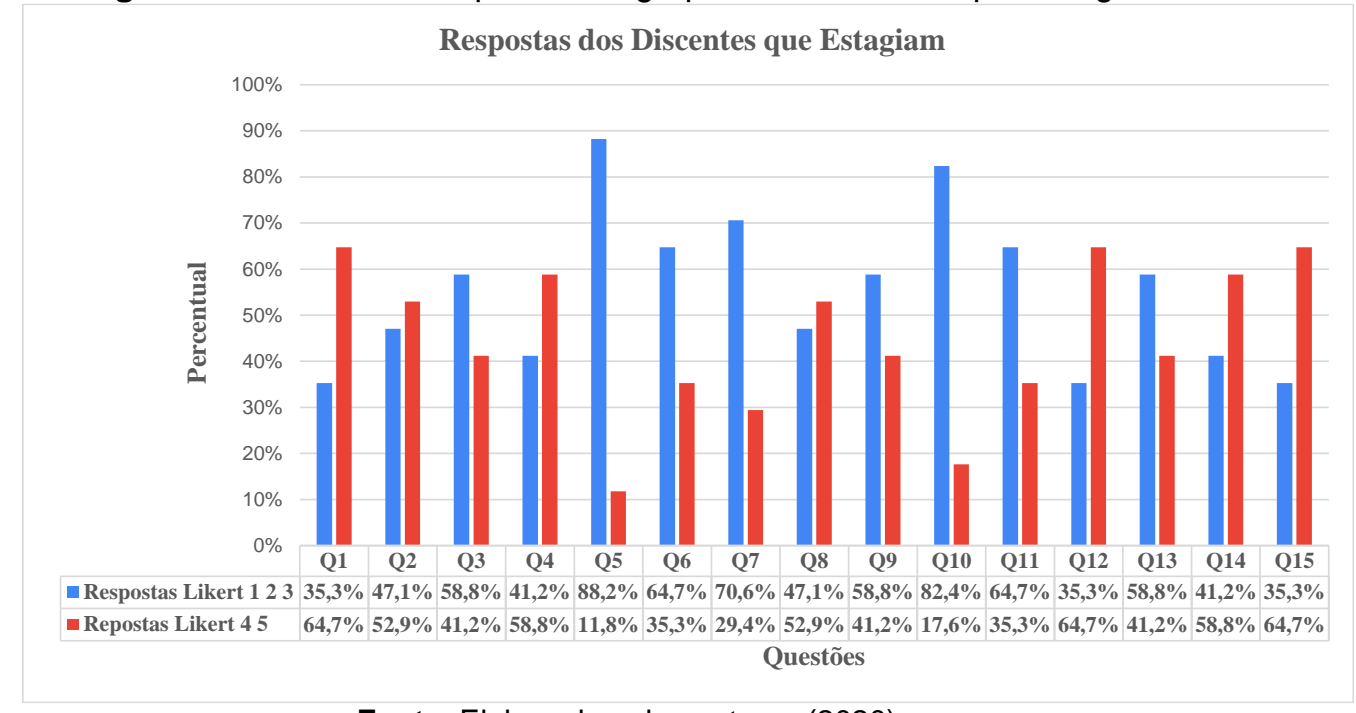

Fonte: Elaborado pelos autores (2020)

Figura 6 - Gráfico de respostas do grupo de estudantes que apenas estudam

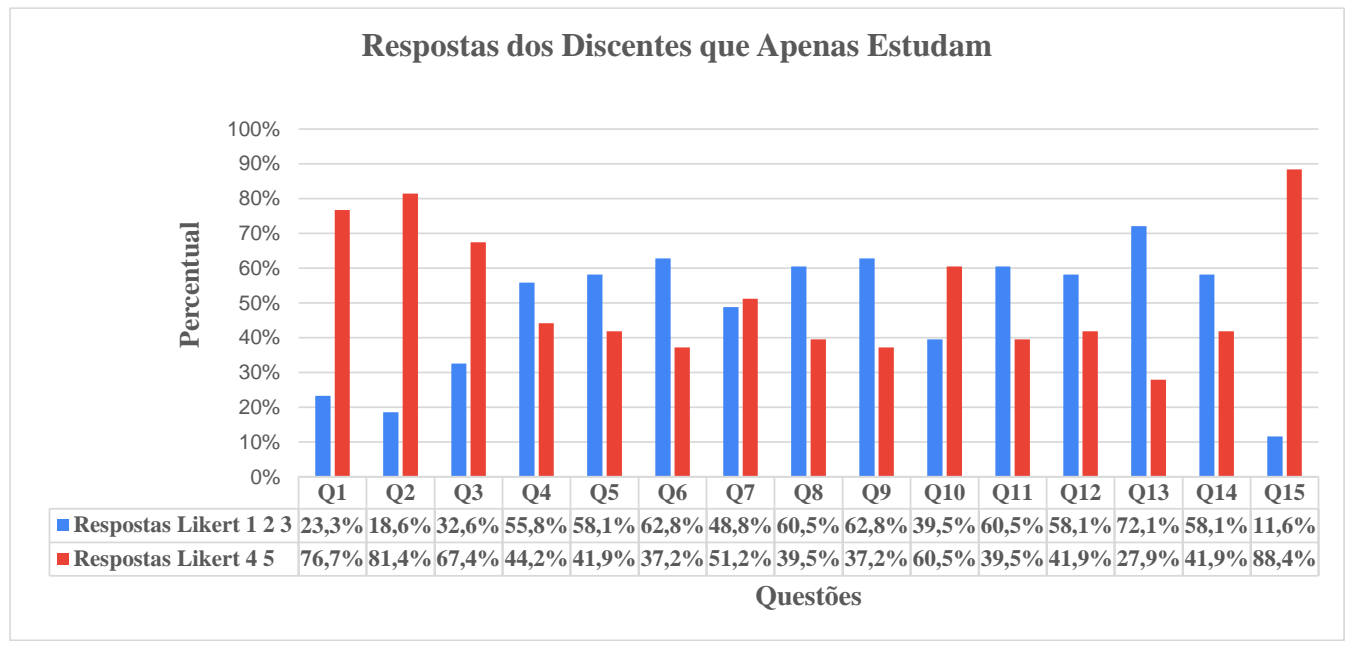

Fonte: Elaborado pelos autores (2020) 
